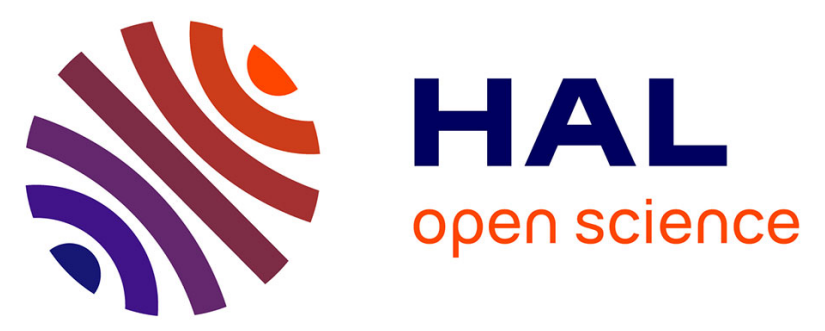

\title{
Crystallization behavior of polypropylene/graphene nanoplatelets composites
}

\author{
Quentin Beuguel, Séverine A.E. Boyer, Daniel Settipani, Gabriel Monge, \\ Jean-Marc Haudin, Bruno Vergnes, Edith Peuvrel-Disdier
}

\section{To cite this version:}

Quentin Beuguel, Séverine A.E. Boyer, Daniel Settipani, Gabriel Monge, Jean-Marc Haudin, et al.. Crystallization behavior of polypropylene/graphene nanoplatelets composites. Polymer Crystallization, 2018, 1 (3), 10.1002/pcr2.10024 . hal-01923597

\section{HAL Id: hal-01923597 \\ https://hal.science/hal-01923597}

Submitted on 15 Nov 2018

HAL is a multi-disciplinary open access archive for the deposit and dissemination of scientific research documents, whether they are published or not. The documents may come from teaching and research institutions in France or abroad, or from public or private research centers.
L'archive ouverte pluridisciplinaire HAL, est destinée au dépôt et à la diffusion de documents scientifiques de niveau recherche, publiés ou non, émanant des établissements d'enseignement et de recherche français ou étrangers, des laboratoires publics ou privés. 


\section{Crystallization behavior of polypropylene/graphene nanoplatelets composites}

Quentin Beuguel, Séverine A.E. Boyer, Daniel Settipani, Gabriel Monge, Jean-Marc Haudin, Bruno Vergnes, Edith Peuvrel-Disdier

MINES ParisTech, PSL Research University, CEMEF - Centre de Mise en Forme des Matériaux, UMR CNRS 7635, CS 10207, 06904 Sophia Antipolis, France

Correspondence to: E. Peuvrel-Disdier (E-mail: edith.disdier@mines-paristech.fr), S.A.E Boyer (Email: severine.boyer@mines-paristech.fr )

ABSTRACT: Interest in graphite fillers has grown since the separation of graphene from graphite by micromechanical cleavage. The object of the paper is to understand the influence of graphene nanoplatelets (GNPs) with different sizes on the crystallization behavior of a polyolefin matrix such as polypropylene (PP), after elaboration by melt mixing and compression molding. Composites with volume fractions of graphene nanoplatelets ranging from 0.3 to 2 vol\% were prepared. The particle dispersion states in the composites were characterized at different scales using Scanning and Transmission Electron Microscopies (SEM and TEM). Polypropylene crystallization and orientation were investigated using optical microscopy, Differential Scanning Calorimetry (DSC) and X-ray diffraction. This paper discusses the strong acceleration of crystallization kinetics due to the presence of GNPs. The micrometric flake-shaped GNPs act as nucleating agent and induce an epitaxial growth of alpha $(\alpha)$ crystalline phase of PP. The nucleating effect is related to the surface of the particles available for heterogeneous nucleation. Radial spherulitic growths are observed from the smallest micrometric particles. The coarsest GNPs, easily oriented by flow, favor PP transcrystallinity, in such a way that (010) plane of PP is parallel to (001) plane of graphene nanoplatelets.

\section{INTRODUCTION}

Since the early 2000's and the separation of graphene from graphite by micromechanical cleavage, ${ }^{1}$ interest in this filler has grown, for its reinforcing and conductive properties. Different paths were developed in order to scale-up graphene production from graphite, avoiding deterioration of its intrinsic properties. ${ }^{2,3}$ One of the most promising paths consists of a ball milling delamination and centrifugation of graphene nanoplatelets, ${ }^{4}$ themselves obtained from graphite after a sulfuric acid 
intercalation and a thermal shock (expanded graphite). ${ }^{5}$ We recently showed that GNPs prepared in this avenue could not be dispersed down to the expected size of a few nanoplatelets by melt mixing in polypropylene, and thus did not result in nanocomposites ${ }^{6}$ However, an effect of the particle size on final properties of polypropylene/graphene nanoplatelets (PP/GNPs) microcomposites was highlighted. ${ }^{6}$ Understanding of PP crystallization behavior ${ }^{7}$ is necessary to control final mechanical properties of composites $^{8}$ and this crystallization is modified by adding mineral ${ }^{9-12}$ or carbonaceous $^{13-20}$ platelets. Generally, the addition of graphene ${ }^{13,16}$ or exfoliated graphite ${ }^{17}$ increases the crystallization rate and accelerates the crystallization kinetics of PP, due to a nucleating effect. In parallel, crystal growth changes from radial to transcrystalline. ${ }^{14,15,17,19}$ If the alpha $(\alpha)$ crystalline phase formation is mainly favored by adding graphene particles, flow ${ }^{14}$ or a high content of graphene ${ }^{18}$ may induce beta $(\beta)$ crystals. Zhao et al. ${ }^{19}$ showed that the presence of graphene decreased the Avrami exponent (characterizing the crystallization kinetics of PP) down to a value close to 2, suggesting a 2D crystal growth. Finally, in the case of reduced graphene, the oxygen content on graphene layer could enhance both crystallization rate and ordered conformation of PP. ${ }^{20}$ Besides, several studies investigated the key role of the mineral nanoplatelets size on PP crystallization. ${ }^{9,11,12}$ Indeed, a small concentration of well dispersed nanoclays, like organically modified montmorillonite, ${ }^{10,11}$ or synthetic talc ${ }^{21}$ had a moderate effect, while large micrometric platelets favored crystallization ${ }^{9}$ and induced high transcristallinity. ${ }^{12}$

The aim of the present study is to investigate the effect of particle size of graphene nanoplatelets (GNPs) on the crystallization behavior of PP matrix. In a previous paper we investigated the dispersion of three GNPs different in size in a PP matrix by melt mixing. The obtained PP/GNP composites were non-exfoliated microcomposites. ${ }^{6}$ However they presented interesting thermal, rheological and mechanical properties close to those of thermoplastic/organoclay or reduced graphene nanocomposites. The crystallization behavior of the PP matrix of these compounds is investigated in this paper. Whereas many papers are reporting the effect of nanoscale graphene on crystallization, this paper is focused on the effect of microscale GNPs.

\section{MATERIALS AND METHODS}

\section{Materials}


Isotactic polypropylene (PP), referenced as Moplen HP400R, was supplied by LyondellBasell (Rotterdam, the Netherlands). The density, the number and weight average molar masses, $M_{n}$ and $M_{w}$, the glass transition temperature, $T_{g}$, the melting point, $T_{m}$, the crystallization temperature (measured at a cooling rate of $-10^{\circ} \mathrm{C} / \mathrm{min}$ ), $T_{c}$, and the Newtonian viscosity $\eta_{0}$ at $180^{\circ} \mathrm{C}$ are listed in Table 1.

\begin{tabular}{c|c|c|c|c|c|c|c} 
Matrix & Density & $M_{n}\left(\mathrm{~g} \cdot \mathrm{mol}^{-1}\right)$ & $M_{w}\left(\mathrm{~g} \cdot \mathrm{mol}^{-1}\right)$ & $\begin{array}{c}T_{g} \\
\left({ }^{\circ} \mathrm{C}\right)\end{array}$ & $\begin{array}{c}T_{m} \\
\left({ }^{\circ} \mathrm{C}\right)\end{array}$ & $\begin{array}{c}T_{c} \\
\left({ }^{\circ} \mathrm{C}\right)\end{array}$ & $\begin{array}{c}\eta_{0} \\
(\mathrm{~Pa} . \mathrm{s})\end{array}$ \\
\hline PP & 0.9 & 59,000 & 205,000 & -10 & 165 & 117 & 1,460
\end{tabular}

Table 1. Main characteristics of PP matrix

Graphene nanoplatelets (GNPs), referenced as KNG-180, KNG-150 and KNG-G5, were commercialized by Knano (Xiamen, China). KNG-180 and KNG-150 GNPs were obtained from graphite through a thermochemical process in three steps: i) graphite was intercalated by sulfuric acid under stirring and then washed and dried, ii) then, it underwent a thermal shock and finally iii) expanded graphite was ultrasonicated in hydroalcoholic solution. From this step, particles are considered as GNPs. ${ }^{5}$ These two GNPs essentially differ by their size (Table 2). An additional ball milling process in a good solvent, followed by centrifugation, enabled to obtain thinner KNG-G5 particles from KNG-180. ${ }^{4}$ According to the dimensions given by the supplier, graphene nanoplatelets of KNG-G5 contain a few tens of graphene sheets (Table 2).

\begin{tabular}{|c|c|c|c|c|c|c|}
\hline $\begin{array}{c}\text { Graphene } \\
\text { nanoplatelets }\end{array}$ & $\begin{array}{c}\text { Bulk } \\
\text { density }\end{array}$ & Density & $\begin{array}{c}\text { Carbon } \\
\text { content } \\
\text { (wt } \%)\end{array}$ & $\begin{array}{c}d \\
(\mu \mathrm{m})\end{array}$ & $\begin{array}{c}e \\
(\mathrm{~nm})\end{array}$ & $\begin{array}{c}\text { Specific } \\
\text { area } \\
\left(\mathrm{m}^{2} / \mathrm{g}\right)\end{array}$ \\
\hline KNG-180 & 0.15 & \multirow{3}{*}{2.25} & $>99.5$ & $8-100$ & $\begin{array}{c}< \\
100\end{array}$ & 35 \\
\hline KNG-150 & 0.2 & & $>98$ & $1-20$ & $<15$ & $30-60$ \\
\hline KNG-G5 & 0.1 & & $>99$ & $0.1-5$ & $<5$ & - \\
\hline
\end{tabular}

Table 2. Bulk density, density, carbon content, particle diameter $d$, thickness $e$ and specific area of GNP, data given by the supplier

\section{Composites Elaboration}

All composites were melt mixed at $T=180^{\circ} \mathrm{C}$ using an internal mixer (Haake Rheomix 600), in three steps: i) PP matrix was molten for $t=2 \mathrm{~min}$ at a rotor speed of $N=20 \mathrm{rpm}$, then ii) GNPs were incorporated for $t=8 \mathrm{~min}$, due to the low GNP bulk density, at the same rotor speed, and finally iii) the samples were mixed for $t=6 \mathrm{~min}$ at a rotor speed of $N=100 \mathrm{rpm}$. After melt mixing, the composites were subsequently cooled down to ambient temperature and compression molded 
during $10 \mathrm{~min}$ at $T=180^{\circ} \mathrm{C}$ in disk shape samples with a diameter of $25 \mathrm{~mm}$ and a thickness of 1.5 $\mathrm{mm}$, using a hydraulic press. Then, the samples were cooled down to ambient temperature, using a water system with a cooling rate about $30^{\circ} \mathrm{C} / \mathrm{min}$. The samples were filled with a volume fraction of GNPs, $\phi_{v o l}$, ranging from 0.3 to 2 vol\%. The GNP volume fraction was determined using Thermogravimetric Analysis (TGA) measurements. ${ }^{6}$

\section{Samples characterization}

Samples were observed using a Transmission Electron Microscope (TEM) (Jeol JEM 1400), operating at $100 \mathrm{kV}$, equipped with a camera (Olympus MORADA SIS). The samples were prepared as ultrathin cuts of $100 \mathrm{~nm}$, using an ultracryomicrotome (Leica FC6) equipped with a diamond knife, at $-100^{\circ} \mathrm{C}$. The length and thickness distributions of GNPs were obtained by measuring at least 100 particles per sample. Additional microscale observations were done on polished surfaces with a Scanning Electronic Microscope (SEM) (Philips XL30 ESEM).

PP crystallization was observed on typically $\sim 5 \mu \mathrm{m}$ thick-films between glass slides under nitrogen atmosphere, using an optical microscope with polarized light (Leica DMRX), camera and gypsum plate, coupled to a hot stage (Mettler HS82). The isothermal crystallization tests were performed at $130^{\circ} \mathrm{C}, 135^{\circ} \mathrm{C}$ and $140^{\circ} \mathrm{C}$, after 3 min holding at $210^{\circ} \mathrm{C}$ to remove all PP crystallization traces and cooling from $210^{\circ} \mathrm{C}$ to the crystallization temperatures at $10^{\circ} \mathrm{C} / \mathrm{min}$. Images were taken every 8 or $15 \mathrm{~s}$ until the complete coverage of the surface by crystalline morphologies. The perimeter of micrometric GNP particles was measured. The relative light transmission intensity was measured on images obtained without gypsum plate, using Image J software. The overall crystallization kinetics of PP, $\alpha(t)$, is defined by:

$$
\alpha(t)=\frac{I_{t}-I_{0}}{I_{\infty}-I_{0}}
$$

where $I_{t}, I_{0}$ and $I_{\infty}$ are respectively the instantaneous (at time $t$ ), initial and final transmitted light intensities. The crystallization half-time $t_{1 / 2}$, corresponding to $\alpha(t)=50 \%$, was noted and crystallization kinetics were fitted by Avrami equation: ${ }^{22}$

$$
\alpha(t)=1-\exp \left(-k t^{n}\right)
$$


where $k$ is the overall crystallization rate constant and $n$ is the Avrami exponent, related to the crystal growth dimensions and the type of nucleation.

The crystalline phases of the different components were studied by wide-angle X-ray diffraction. The crystal structure of the $\alpha$ phase of isotactic PP is described by the monoclinic primitive cell: $a$ $=6.63 \AA, b=20.78 \AA, c=6.50 \AA$ (chain axis), $\alpha=\gamma=90^{\circ}$ and $\beta=99.5^{\circ}$, while the hexagonal primitive cell of GNPs is defined by: $a=b=2.46 \AA, c=6.71 \AA, \alpha=\beta=90^{\circ}$ and $\gamma=120^{\circ}$. For calculations on PP, the $(\boldsymbol{a}, \boldsymbol{b}, \boldsymbol{c})$ framework of reference was replaced by the $(\boldsymbol{A}, \boldsymbol{b}, \boldsymbol{c})$ orthogonal one, $\boldsymbol{A}$ being the vector of the reciprocal lattice associated to $\boldsymbol{a}$.

In order to describe crystalline orientations, X-ray diffraction was carried out on polished disks at ambient temperature, using a diffractometer (Empyrean model PANalytical), equipped with an Eulerian cradle, with $\mathrm{Cu} \mathrm{K \alpha}$ wavelength of $0.154 \mathrm{~nm}$, generated at $45 \mathrm{kV}$ and $30 \mathrm{~mA}$. The (110) and (040) pole figures of PP, as well as (002) pole figure of graphene (diffraction angles $2 \theta=14^{\circ}$, $16.7^{\circ}$ and $25.6^{\circ}$, respectively) were recorded for the PP matrix and composites filled with $\phi_{v o l} \sim 1.8$ vol\% of GNPs. The normal direction of the specimen (OZ axis) is centrally located on pole figures. $\mathrm{OX}$ and OY axes are located in the specimen plane. The measurements were carried out by steps of $5^{\circ}$ in reflection and in transmission, for an azimuthal angle $\chi$ (angle between $\mathrm{OZ}$ and the normal to the diffracting plane) ranging from $0^{\circ}$ to $65^{\circ}$ and from $60^{\circ}$ to $90^{\circ}$, respectively. The sample was rotated on $360^{\circ}$ by steps of $5^{\circ}$ for each $\chi$. Over $360^{\circ}$ rotation, azimuthal sweeps for unoriented specimens show a maximum intensity difference of $\pm 20 \%$. This was used as an error bar for the intensity in 1D diffractograms.

Average state of orientation in PP matrix was quantified by the values of $<\cos ^{2} \phi_{j, i}>$, which represent the mean-square cosines of the angles $\phi_{j, i}$ between a crystallographic axis $j(j=\boldsymbol{A}, \boldsymbol{b}, \boldsymbol{c})$ and a macroscopic axis $i(i=\mathrm{OX}, \mathrm{OY}, \mathrm{OZ})$. It is geometrically represented by a point $\mathrm{N}$ inside a reference equilateral triangle: NH, NK and NL are the lengths of the perpendicular segments drawn from $\mathrm{N}$ to the different triangle sides, and:

$$
\left\langle\cos ^{2} \phi_{j, O X}\right\rangle=\mathrm{NH},\left\langle\cos ^{2} \phi_{j, O Y}\right\rangle=\mathrm{NK},\left\langle\cos ^{2} \phi_{j, O Z}\right\rangle=\mathrm{NL}
$$

One calculates first the quantities: 


$$
\left\langle\cos ^{2} \chi_{h k l, i}\right\rangle=\frac{\int_{0}^{\pi / 2} \int_{0}^{2 \pi}\left(\chi_{i}, \beta_{i}\right) \cos ^{2} \chi_{i} \sin \chi_{i} d \chi_{i} d \beta_{i}}{\int_{0}^{\pi / 22 \pi} \int_{0}^{2 \pi}\left(\chi_{i}, \beta_{i}\right) \sin \chi_{i} d \chi_{i} d \beta_{i}}
$$

for the (110) and (040) pole figures, I being the corrected and normalized diffracted intensity at the

position of the pole figure defined by the $\left(\chi_{i}, \beta_{i}\right)$ angles. The $\left\langle\cos ^{2} \phi_{j, i}\right\rangle$ values are then deduced from geometrical calculations in the $(\boldsymbol{A}, \boldsymbol{b}, \boldsymbol{c})$ frame of reference.

All diffractograms were obtained in reflection at $\chi=0^{\circ}$ over a $2 \theta$ range from $4^{\circ}$ to $70^{\circ}$ by steps of $0.08^{\circ}$. This characterization was also carried out on polished disks at ambient temperature, using a PANalytical X'pert Pro MPD in the same operating conditions as for pole figures. The peak areas were fitted with Pearson VII functions adapted to the crystalline phases, ${ }^{23}$ using Origin software.

Differential scanning calorimetry (DSC) measurements were performed on $5 \mathrm{mg}$ samples with a Perkin Elmer DSC 4000. Thermograms were recorded for cooling from $210^{\circ} \mathrm{C}$ to $25^{\circ} \mathrm{C}$ and then heating from $25^{\circ} \mathrm{C}$ to $210^{\circ} \mathrm{C}$ both at $10^{\circ} \mathrm{C} / \mathrm{min}$, after erasing the thermomechanical history of samples by applying a 3 min isothermal step at $210^{\circ} \mathrm{C}$. The PP crystallinity ratio $X_{c}$ was defined as the crystallization enthalpy of the sample (accurate to $\pm 20 \mathrm{~J} / \mathrm{g}$ ) divided by the crystallization enthalpy of $100 \%$ crystalline PP $(207 \mathrm{~J} / \mathrm{g}) .{ }^{24}$ Melting $T_{m}$ and crystallization $T_{c}$ temperatures (accurate to $\pm 1^{\circ} \mathrm{C}$ ) were determined at the maximum of the enthalpy peaks.

\section{RESULTS AND DISCUSSION}

Figure 1 shows the number size distributions of GNPs in microcomposites with $\phi_{v o l} \sim 1$ vol\%, measured in TEM images on at least 100 particles per sample. 

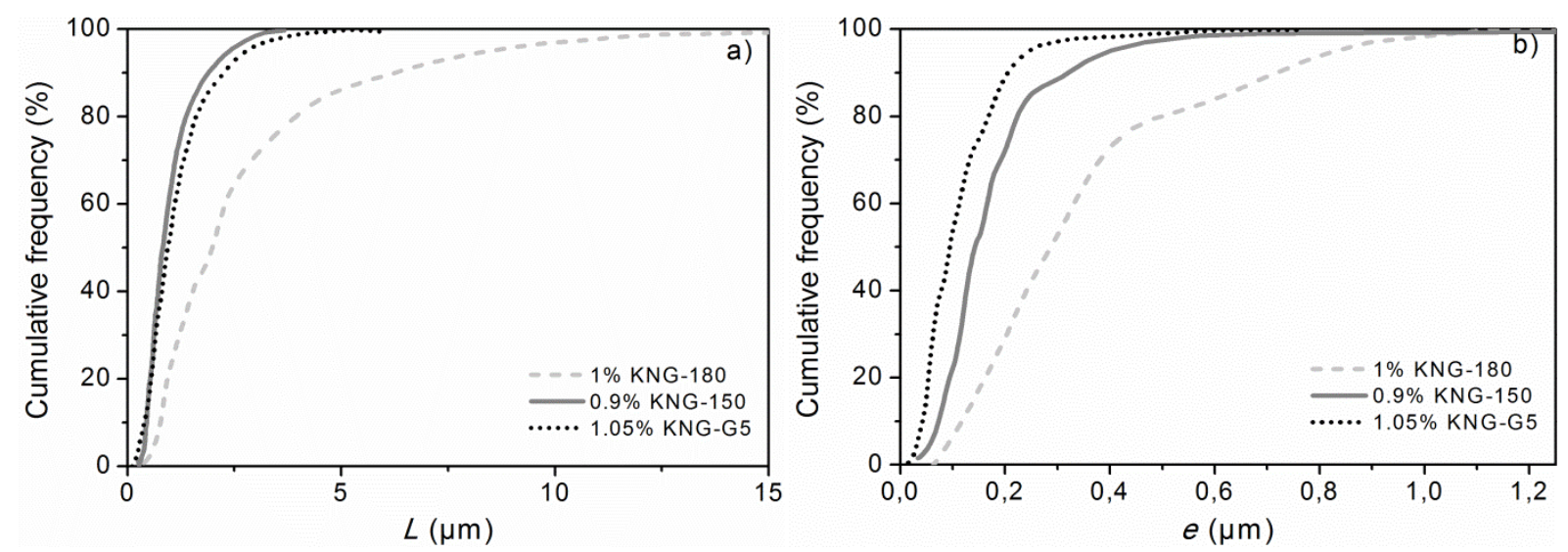

Figure 1. GNP length $L$ (a) and thickness $e$ (b) distributions in the microcomposites measured by TEM

GNPs dispersed in the PP matrix have a flake-like shape. ${ }^{6}$ Their length is mainly micrometric and only some of them are submicronic. ${ }^{6}$ KNG-180 are the longest [Figure 1(a)] and the thickest [Figure 1(b)] particles. KNG-150 particles are slightly shorter and clearly thicker than those of KNG-G5. In more details, 10\%, 30\% and 70\% of KNG-G5, KNG-150 and KNG-180 particles are thicker than $0.2 \mu \mathrm{m}$, respectively [Figure 1(b)].

Figure 2 presents a SEM (a) and an optical microscope (b) image of PP/0.3 vol\% KNG-G5 microcomposite. The shape of the GNPs particles in the microcomposites is surprising [as seen by optical microscopy in Figure 2(b)]. SEM observations after polishing of the surface depicted flakelike particles [Figure 2(a)]. However, large objects were observed by optical microscopy [Figure 2(b)]. Optical observations are performed on very thin samples ( $\sim \mu \mathrm{m}$ thickness) in molten matrix. These samples were observed after a strong compression in the molten state between two glass slides. The compression induces an orientation of the flakes particles in parallel to the flow direction and to the specimen surface resulting in the observation of large objects. The presence of large objects can also be guessed from SEM images where dark shadows are observed around the particles [Figure 2(a)]. This shadow is due to the conductive character of GNPs. ${ }^{25}$ The cross-section of flake-like particles is observed by SEM after polishing. There are some interactions between beam electrons and the graphene, leading to a shadow around the flake cross-section due to the presence of graphene located behind the matrix surface. 

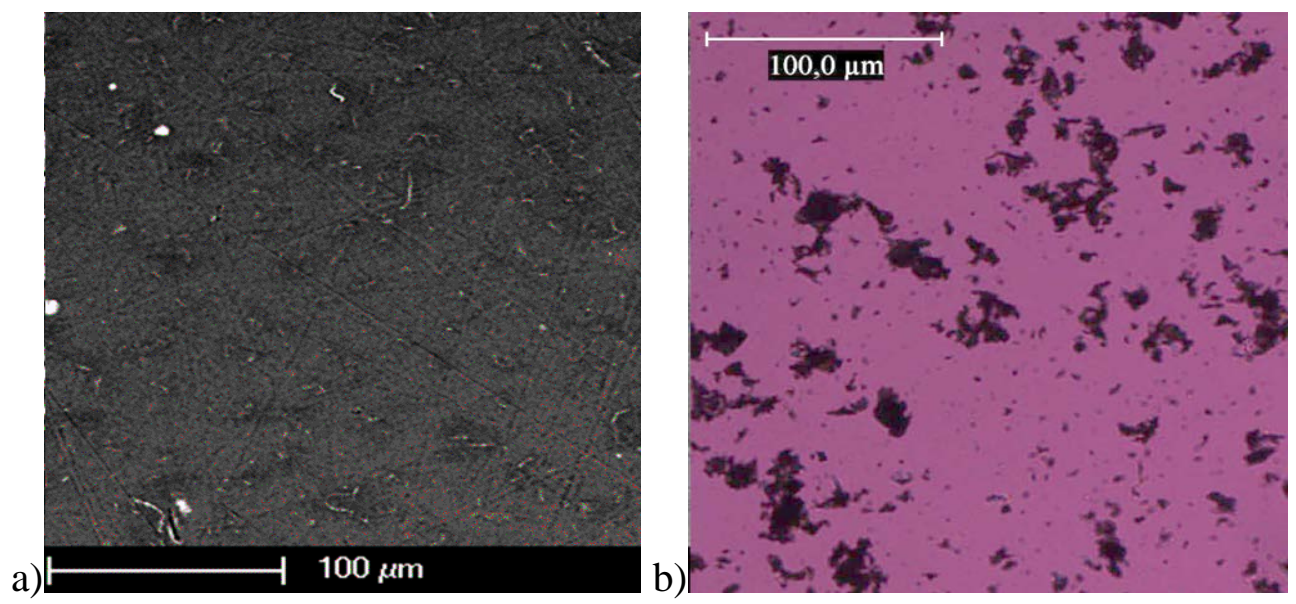

Figure 2. PP/0.3 vol\% KNG-G5 microcomposite observed by SEM after surface polishing (a) and optical microscopy in the molten state between glass slides (b)

Optical images (Figure 3) show the PP crystalline growth, from the beginning of the isothermal stage $\left(T=135^{\circ} \mathrm{C}\right)(\mathrm{a}, \mathrm{d}, \mathrm{g}, \mathrm{f})$ to the complete coverage of the surface by crystalline entities (c, f, i, l), through an intermediate stage (b, e, h, k), for PP matrix (a-c) and PP/GNP composites filled with $\sim 0.3$ vol\% of KNG-180 (d-f), KNG-150 (g-i) and KNG-G5 (j-l), at the same magnification. Crystallization kinetics were measured on 0.3 vol\% of GNPs in order to avoid too many GNP particles in the field of observation for the sample thickness used (typically $\sim 5 \mu \mathrm{m}$ ) and to be able to clearly observe the PP crystallization. 

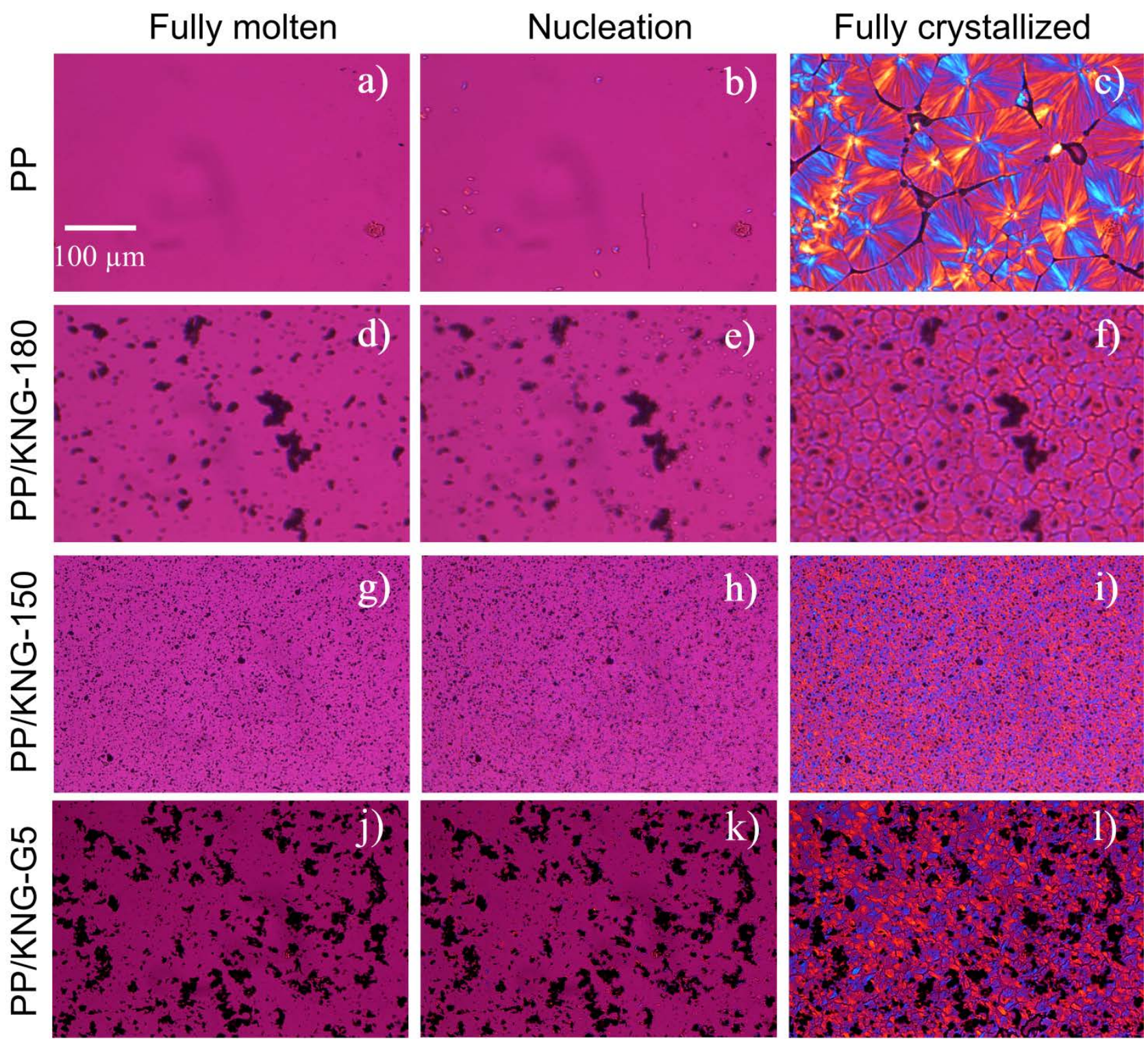

Figure 3. Optical images of PP crystallization at $T=135^{\circ} \mathrm{C}$, for PP matrix (a-c) and PP/KNG-180 (d-f), KNG-150 (g-i) and KNG-G5 (j-1) microcomposites, with $\phi_{v o l .} \sim 0.3$ vol\% of GNPs. All observations are reported with the same magnification on $5 \mu \mathrm{m}$ thickness films

PP matrix crystallizes in the form of spherulites of the monoclinic $\alpha$ phase [Figures 3(a-c)] from some nucleating points (impurities, defects, ...), randomly located as classically reported in the literature. ${ }^{26}$ The crystallization kinetics of the PP matrix is slow, characterized by a crystallization half-time $t_{1 / 2}$ around $900 \mathrm{~s}$ (Figure 4). Nucleation seems to exhibit some sporadic-in-time character: spherulites with diameters ranging from 70 to $200 \mu \mathrm{m}$ can be identified and curved boundaries are observed. Two types of defects are also noticed: voids at triple junctions and interspherulitic ruptures. Such defects were already described in a previous work. ${ }^{7}$ 
The presence of GNPs accelerates the PP crystallization kinetics ${ }^{17}$, particularly in the case of KNG150 and KNG-G5 compared to KNG-180, with crystallization half-times at $135^{\circ} \mathrm{C}$ equal to $91 \mathrm{~s}$, $131 \mathrm{~s}$ and $145 \mathrm{~s}$, respectively [Figures 4 and 5(a)], assuming that the filler content is enough similar for the different composites. This is associated with an important decrease of the spherulite diameter compared to the neat PP, which is about $10 \mu \mathrm{m}$ for KNG-150, in the range of 30-50 $\mu \mathrm{m}$ for KNG-180, seemingly intermediate and more difficult to estimate for KNG-G5 (Figure 3). Crystal nucleation seems to start from the surface of visible micrometric GNPs (thickness $e>0.2$ $\mu \mathrm{m})$ in optical images [Figures $3(\mathrm{e}, \mathrm{h}, \mathrm{k})]$. A similar result was reported on systems filled with talc. ${ }^{9}$ Since the crystal growth rate is only temperature dependent for a given polymer, ${ }^{7}$ the ranking of crystallization kinetics between the different microcomposites should be related to the total nucleation surface. The total surface corresponding to the particles was estimated in $2 \mathrm{D}$ as the total perimeter developed by the particles. The total perimeter developed by nucleating particles, with a thickness larger than $0.2 \mu \mathrm{m}$ for an image size of $170,000 \mu \mathrm{m}^{2}(\sim 500 \times 340 \mu \mathrm{m})$, is around 46,000, 17,000 and 5,000 $\mu \mathrm{m}$ for KNG-150, KNG-G5 and KNG-180 composites, respectively. It is worth pointing out that the total developed perimeter measurements only consider the visible nucleating micron size particles, excluding the GNP nanoparticles observed by TEM, and take into account the size of the particles and their number. Considering a same crystal growth rate close to $0.05 \mu \mathrm{m} / \mathrm{s}$ (value experimentally measured in this work and in agreement with the literature), ${ }^{7}$ the different crystallization kinetics (Figure 4) are explained by the area developed by the nucleating particles.

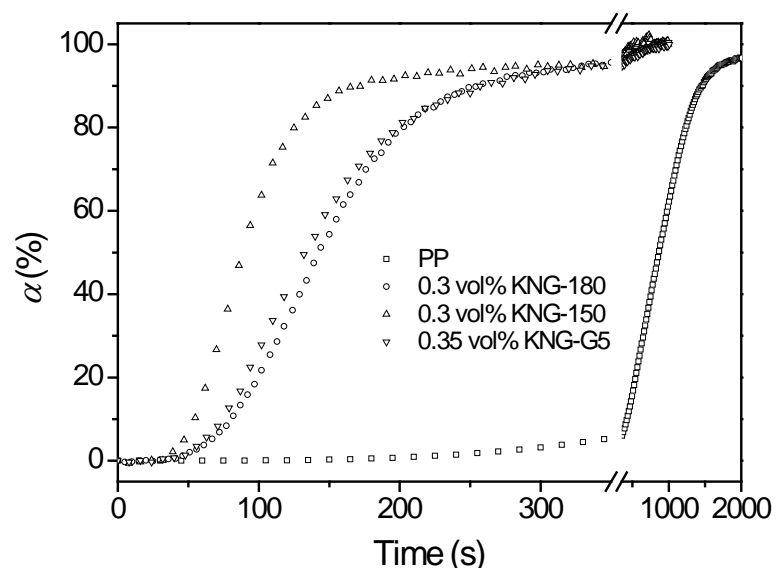

Figure 4. Crystallization kinetics at $135^{\circ} \mathrm{C}$ for PP matrix and PP/KNG-180, KNG-150 and KNG-G5 microcomposites, with $\sim 0.3$ vol\% of GNPs. 
The influence of the crystallization temperature on the overall kinetics was investigated in Figure 5, characterized by the crystallization half-time $t_{1 / 2}$ [Figure 5(a)] and the Avrami exponent $n$ [Figure 5(b)]. The difference between PP matrix and composites increases with increasing temperature. This demonstrates the efficiency of heterogeneous nucleation on GNP surface, while crystallization of neat PP is considerably slowed down at high temperature. Furthermore, the differences between composites are amplified at $140^{\circ} \mathrm{C}$, which underlines their specific nucleating behavior and confirms our analysis in previous paragraph. Avrami exponents $n$ were also estimated for PP and microcomposites [Figure 5(b)]. For the neat PP (79 $\mu$ m-thick specimens), it decreases from 2.5 to 2.1, which could reflect the trend to a two-dimensional growth with increasing spherulite size. For microcomposites (thickness $5 \mu \mathrm{m}$ ), it increases from 1.7-2.5 (at $130^{\circ} \mathrm{C}$ ) to $2.6-3$ (at 135 and $140^{\circ} \mathrm{C}$ ). In this complex situation (thin films containing nucleating particles), it is often difficult to interpret the values of the Avrami exponents. Theoretically, a value of 3 corresponds to instantaneous nucleation and to 3D-growth. This could be consistent with the growth of small spherulites from nucleating particles observed in Figure 3.
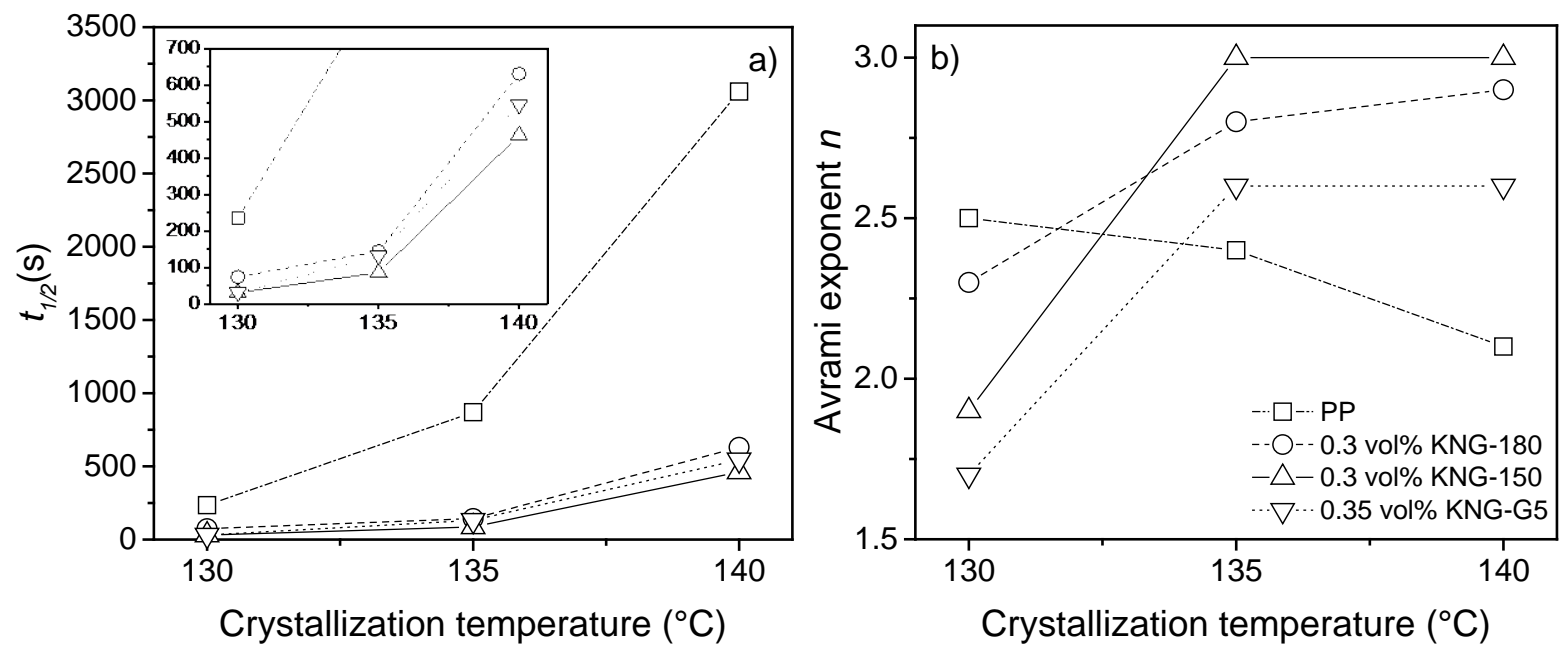

Figure 5. Crystallization half-time $\left(t_{1 / 2}\right)$ (insert represents a zoom on low values of $\left.t_{1 / 2}\right)$ (a) and Avrami exponent (b) at 130, 135 and $140^{\circ} \mathrm{C}$ for PP matrix; PP/KNG-180, KNG-150 and KNG-G5 microcomposites with $\sim 0.3$ vol\% of GNPs. The lines are just to guide the eyes

In addition, GNP size seems to influence the orientation of crystalline lamellae (Figure 6). Indeed, transcrystalline growth ${ }^{14}$ perpendicular to the particle surface is observed for large anisotropicshaped GNPs, as illustrated by the similar shape of the envelop of the final crystalline entities and the particle (see arrow on Figure 6). Conversely, the crystal growth seems to be radial for small isotropic particles (see arrow on Figure 6). The presence of interspherulitic ruptures can also be 
noticed. ${ }^{7}$ At the end of crystallization, the growth of the spherulites is hindered by the presence of their neighbors and some secondary crystallization may occur. Finally, PP morphologies are smaller in the presence of KNG-150 than in the presence of KNG-G5 and KNG-180 [Figures 3(f, i, l)], as mentioned above and in agreement with the higher number of nucleating points (and the perimeter values). These geometrical considerations could have some influence on the values of the Avrami exponent (see above).

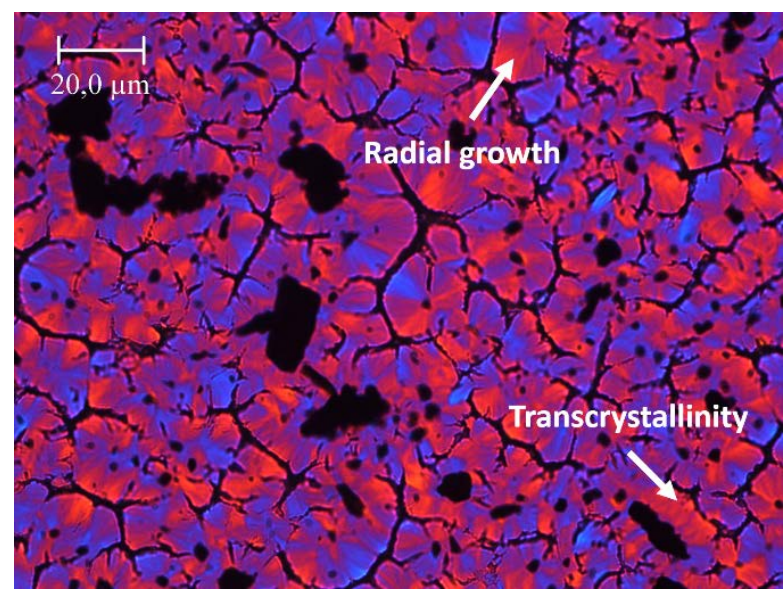

Figure 6. Enlarged optical image of PP/0.3 vol\% KNG-180 microcomposite at the end of the crystallization.

The (110) and (040) pole figures of PP, and the (002) pole figure of GNPs are represented for PP matrix and PP/KNG-180, KNG-150, KNG-G5 microcomposites with $\phi_{\text {vol. }} \sim 1.8$ vol\% of GNPs (Figure 7). The relative intensity values correspond to the relative amount of crystallographic plane normals and 1 representing the average density. 

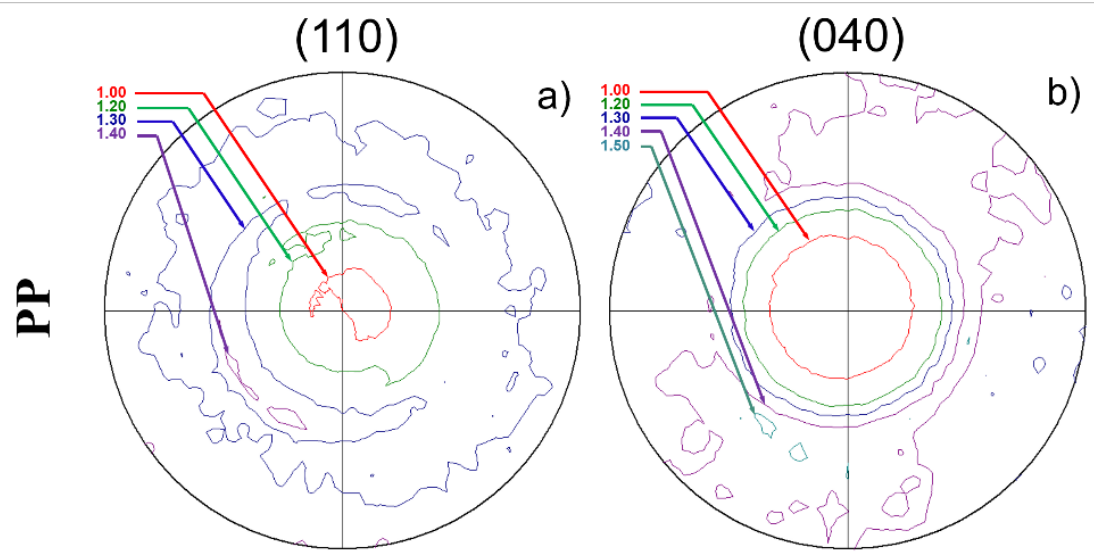

b)
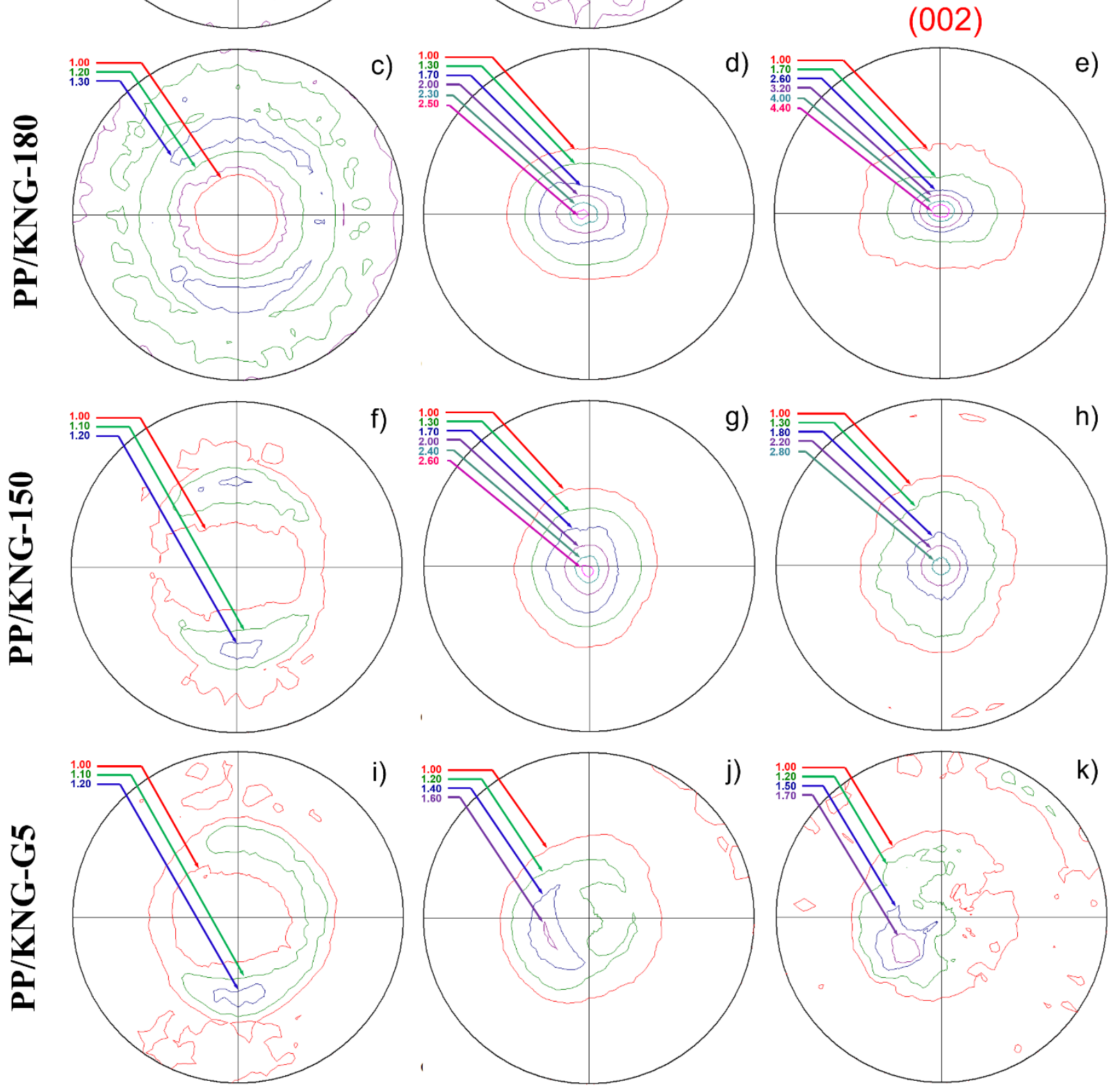

Figure 7. Pole figures of PP: (110) (a, c, f, i) and (040) (b, d, g, j), and of GNPs: (002) (e, h, k), for PP matrix (a, b) and PP/KNG-180 (c, d, e), KNG-150 (f, g, h) and KNG-G5 (i, j, k) composites, with 1.8 vol\% of GNPs 
All pole figures present relatively circular and centered iso-intensity lines, due to a symmetry of revolution about the normal of the disk, which results from the compression molding process. The degree of orientation is low in compression-molded PP matrix [Figures 7(a, b)], in agreement with a spherulitic morphology. On the contrary, high intensity values are obtained in the pole figure center $\left(\chi=0^{\circ}\right)$ of (040) PP and (002) graphene stack in the case of PP/KNG-180 and PP/KNG-150 microcomposites. The maximum intensity of the (002) graphene stack pole figure is higher for KNG-180 than for KNG-150, in agreement with the large thickness measured [Figure 1(b)]. The maximum intensity in the center of (040) PP pole figures is similar for KNG-180 and KNG-150 based composites. These results show that flow orients GNPs parallel to the disk surface, which influences PP crystallization in such a way that (010) PP planes are parallel to (002) graphene stack ones, i.e., to the disk surface.

These orientation relationships are in agreement with the transcrystalline growth of PP crystalline lamellae on coarse GNPs revealed by optical microscopy (Figure 6), (010) planes being usually involved in epitaxy of the $\alpha$ phase. ${ }^{27}$ Similar results were obtained by Branciforti et al. ${ }^{12}$ in the case of PP filled with talc microparticles. The level of orientation is much lower in PP/KNG-G5. Taking into account previous results (Figures 3, 4 and 5), the behavior could be expected to be intermediate between those of PP/KNG-180 and PP/KNG-150, and even closer to that of PP/KNG-150. In all the pole figures, the orientation of (110) planes is moderate, with weak maxima at about $50^{\circ}$ from the center of the projection.

The average orientation of the $\boldsymbol{A}, \boldsymbol{b}, \boldsymbol{c}$ axes of the $\alpha$ PP crystalline phase was calculated from pole figures for the PP matrix and PP/GNP microcomposites and displayed in a triangular representation (Figure 8). 


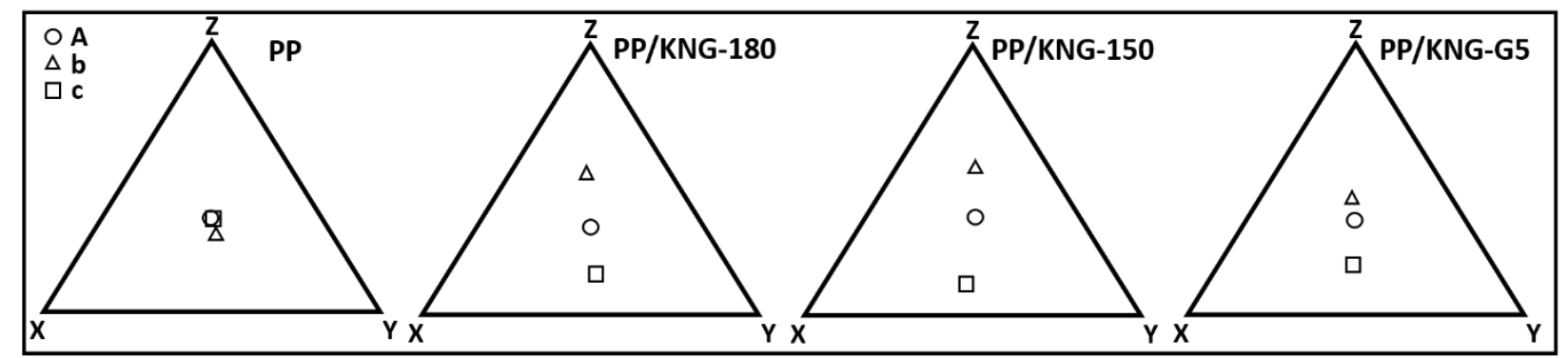

Figure 8. Orientation triangles of PP for the neat matrix and PP/KNG-180, KNG-150, KNG-G5 microcomposites with $~ 1.8 \mathrm{vol} \%$ of GNPs, where $Z$ axis represents the specimen normal, and $X, Y$ axes are in the specimen plane.

These calculations confirm that neat PP is nearly isotropic. For the composites, the symmetry of revolution about the normal of the disk ( $Z$ axis) is clearly established, which implies that the choice of the $\mathrm{X}, \mathrm{Y}$ axes in the specimen plane does not matter. The level of orientation is higher and similar in PP/KNG 180 and PP/KNG 150 composites, but lower in PP/KNG G5. The type of orientation is the same for the three composites. It is confirmed that the $\boldsymbol{b}$ axis, normal to the (010) plane, tends to be aligned along the normal direction $\mathrm{Z}$. Additional information is provided by the triangles. The chain axis $\boldsymbol{c}$ tends to be preferentially oriented in the specimen plane. This is consistent with an epitaxial crystallization mechanism, GNPs being also oriented parallel to the specimen plane. Curiously, $\boldsymbol{A}$ is distributed isotropically. This means that the crystallographic texture cannot be reduced to the orientation to an equivalent single crystal. It could also explain the $50^{\circ}$ angle mentioned above for the orientation of the (110) planes. Calculations in a single crystal would lead to a value of $70^{\circ}$.

Figure 9 presents the diffractograms of PP/KNG-180 composites with different volume fractions ( $\phi_{\text {vol. }}=0-1.7$ vol\% of GNPs), at $\chi=0^{\circ}$. Only characteristic peaks of $\alpha$ PP crystalline phase are observed on diffractograms [Figure 9(a)]. For all systems, peak intensity values are similar for (130), (111), ( $\overline{1} 31+041)$ and (220) PP reflections. However, the integrated intensities of the (110) peak at $2 \theta=14^{\circ}$ and the (040) peak at $2 \theta=16.7^{\circ}$ respectively decrease and increase with GNP concentration [Figure 9(b)], in agreement with pole figures (Figure 7). The integrated intensity values of (110) and (040) PP reflections peaks [Figures 10(a, b)] and those of (002) GNP stack peak [Figure 10(c)] are plotted as a function of GNP volume fraction. 

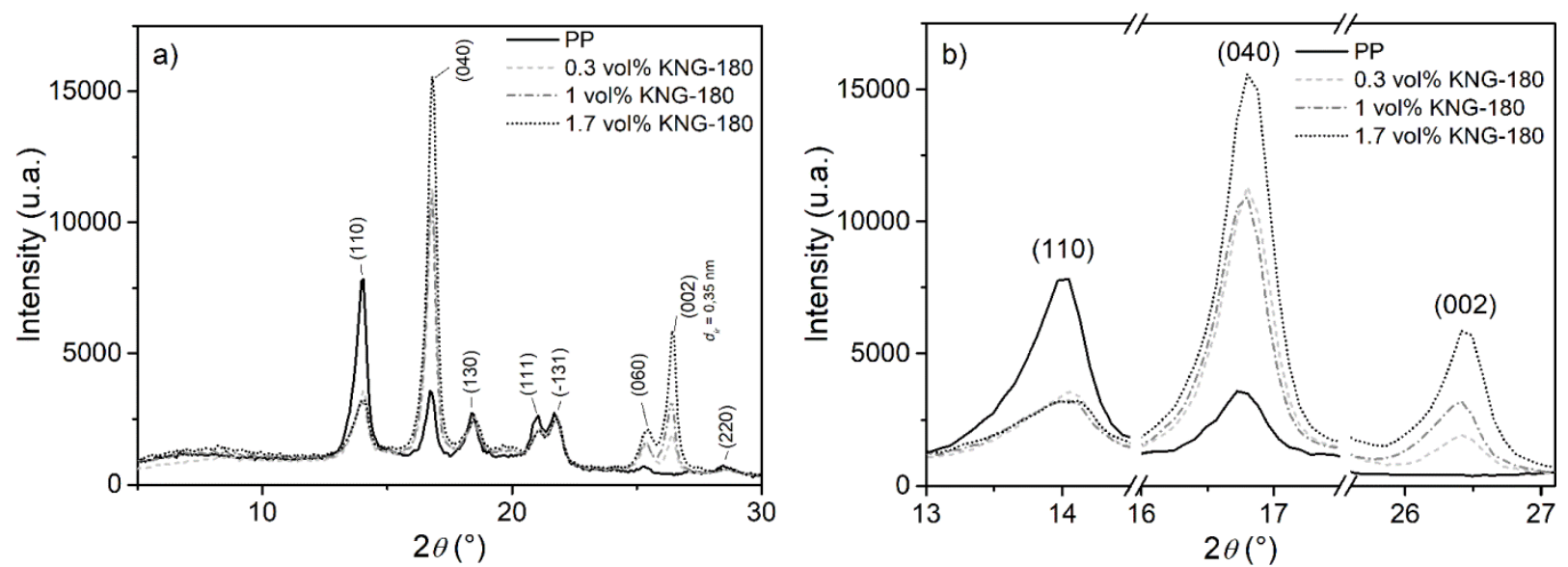

Figure 9. (a) Diffractograms of PP matrix and PP/KNG-180 microcomposites at $\chi=0^{\circ}$, (b) zooms for the (110), (040) and (002) reflections
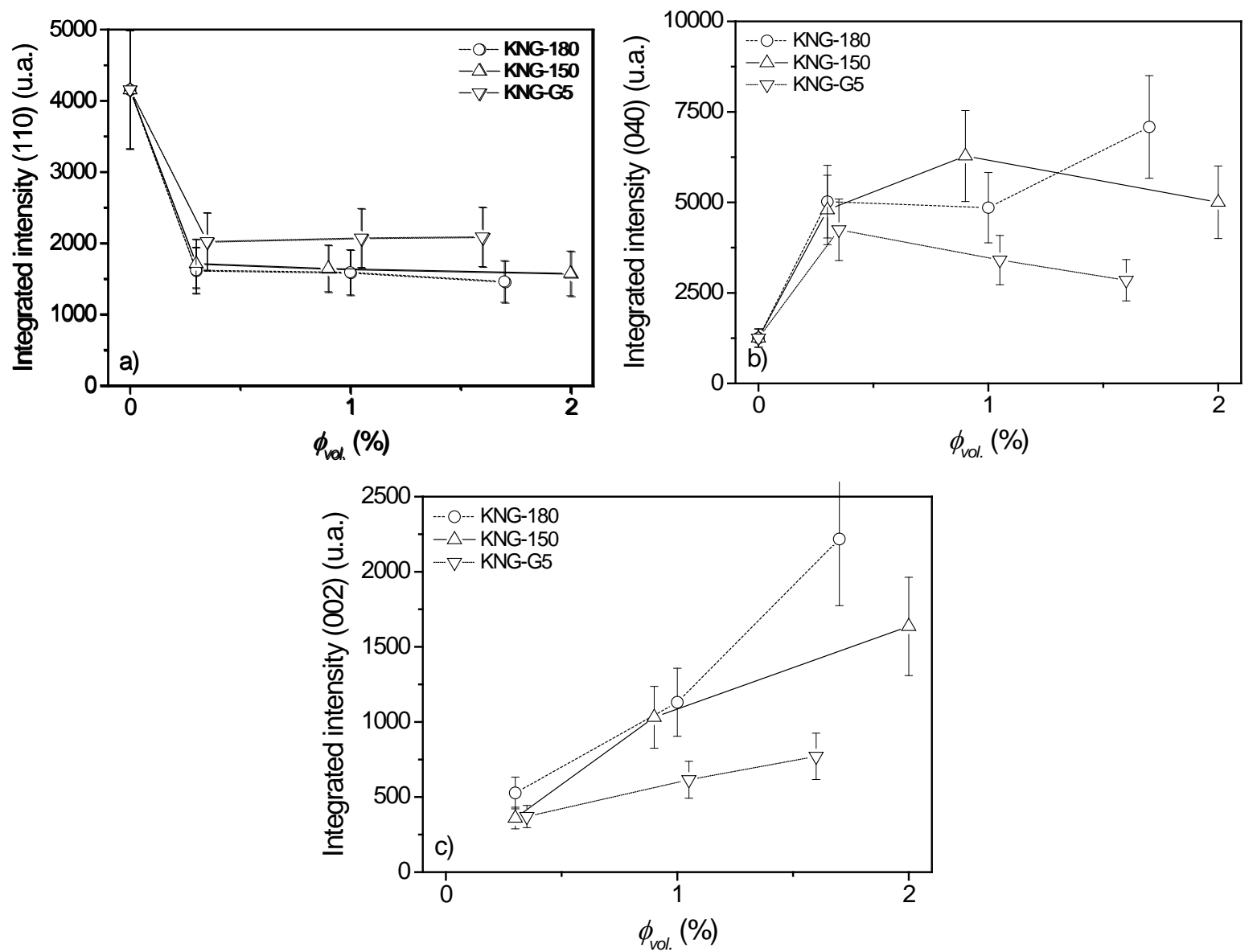

Figure 10. Integrated diffraction intensity of (110) (a), (004) (b) and (002) (c) reflections for PP/GNP microcomposites at $\chi=0^{\circ}$ as a function of GNP volume fraction $\phi_{v o l}$. The lines are just to guide the eyes

The integrated intensity of (110) PP peak highly decreases with the addition of KNG-180 and KNG-150, while the decrease is less pronounced by adding KNG-G5 [Figure 10(a)]. Moreover, the 
addition of thicker KNG-180 and KNG-150 fillers strongly increases the integrated intensity of the (040) peak. On the other hand, the influence of GNP volume fraction on integrated intensity values is very low, as reported by Branciforti et al. ${ }^{12}$ for PP/talc microcomposites. This result suggests a saturation of crystalline orientation from low GNP volume fractions ( $\phi_{v o l} \sim 0.3$ vol\%). Finally, an increase of the graphene stack characteristic peak (002) is observed with both the volume fraction and the thickness of GNP [Figure 1(b)]. This result highlights the lower number of ordered stacks for PP/KNG-G5 composites.

Figure 11 shows the DSC thermograms, during the crystallization (a) and the melting (b), for PP/KNG-180 composites with different volume fractions ( $\phi_{\text {vol. }}=0-1.7$ vol\% of GNPs).
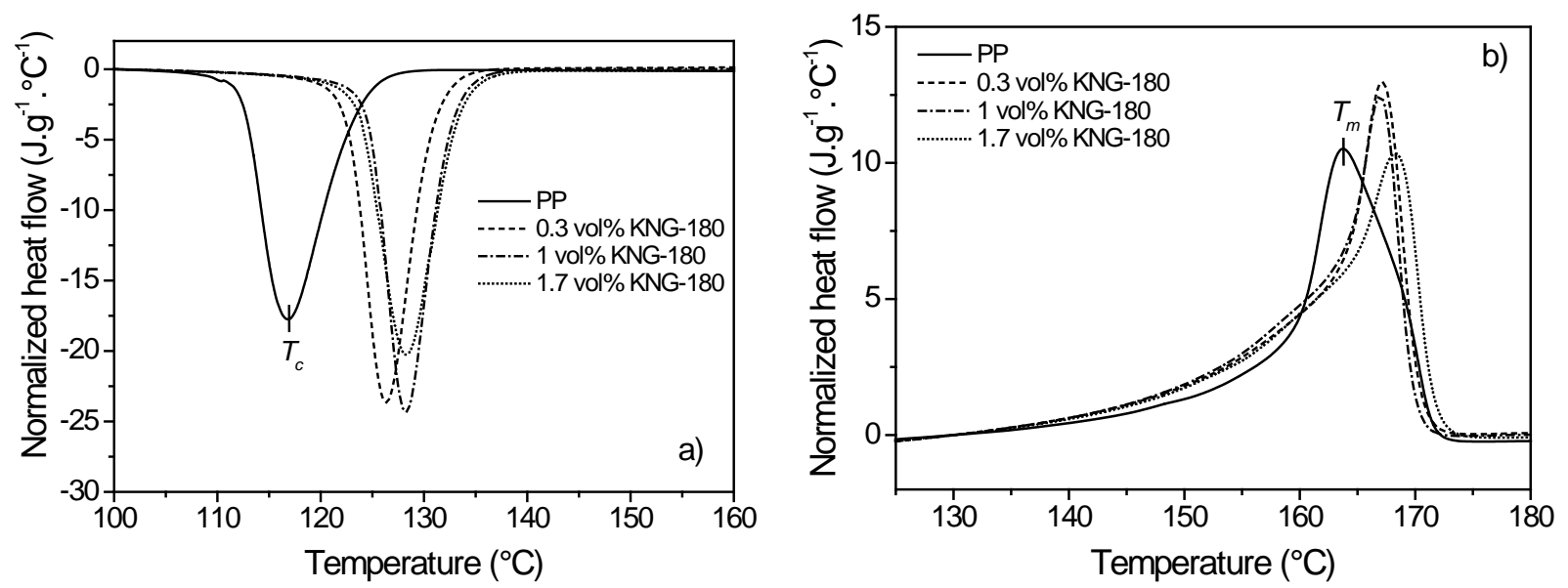

Figure 11. DSC thermograms for PP/KNG-180 composites, during the crystallization after a first melting step to erase thermal history (a) and the second melting (b). The cooling and heating rates are of $10^{\circ} \mathrm{C} / \mathrm{min}$

Only one melting peak (but with a shoulder) was clearly observed for PP matrix [Figure 8(b)] while two were highlighted during the first heat-up ramp (not presented here), characterizing two different populations of crystalline lamellae. ${ }^{27}$ This result was probably related to the crystallization temperature $T_{c}$ respectively below $115^{\circ} \mathrm{C}^{7}$ using the hydraulic press with a cooling rate close to $30^{\circ} \mathrm{C} / \mathrm{min}$, and above $115^{\circ} \mathrm{C}$ for a slower cooling using DSC $\left(10^{\circ} \mathrm{C} / \mathrm{min}\right)$. Indeed, in Figure 11(a), $T_{c} \approx 117^{\circ} \mathrm{C}$ for PP matrix, i.e., slightly above $115^{\circ} \mathrm{C}$. Otherwise, a single melting peak was also detected for all other PP/GNP microcomposites, as observed for PP/KNG-180 systems. The melting $\left(T_{m}\right)^{16,17}$ and crystallization $\left(T_{c}\right)^{16,28}$ temperatures increased with the addition of GNP in agreement with the crystallization modifications observed in Figures 3, 4 and 5. However, for all systems, the 
melting and crystallization enthalpies were similar, leading to an average crystallinity ratio $X_{c}$ of around $62 \%$.

Linear viscoelastic mechanical properties were determined for the same samples. ${ }^{6}$ A higher storage modulus was evidenced for PP/KNG-G5 microcomposites. This reinforcement of mechanical properties was attributed to the intrinsic properties of KNG-G5 due to its higher aspect ratio. The crystalline state (crystalline degree and/or spherulite size) of $\mathrm{PP}^{29,30}$ and its orientation ${ }^{31}$ in the presence of GNPs could also play a role. The present paper shows that although PP in microcomposites depicts similar average crystalline degree, the size of the spherulites as well as the crystalline orientation can be very different. The PP/KNG-150 microcomposites present the smallest spherulites (linked to the nucleation efficiency related to the total surface of micrometric particles) and the highest level of orientation. In the present case, where the flake particles are oriented parallel to the specimen surface (linked to the compression molding of the sample), there is no evident correlation between the crystalline properties of PP and the enhancement of storage modulus. It would suggest that, in these microcomposites, the mechanical properties are dominated by the intrinsic properties of the GNPs (aspect ratio) and the crystallization properties would only have a secondary influence.

Figure 12 shows the evolution of the crystallization $T_{c}$ (a) and melting $T_{m}$ (b) temperatures as a function of GNP volume fraction for PP matrix and PP/GNP composites.
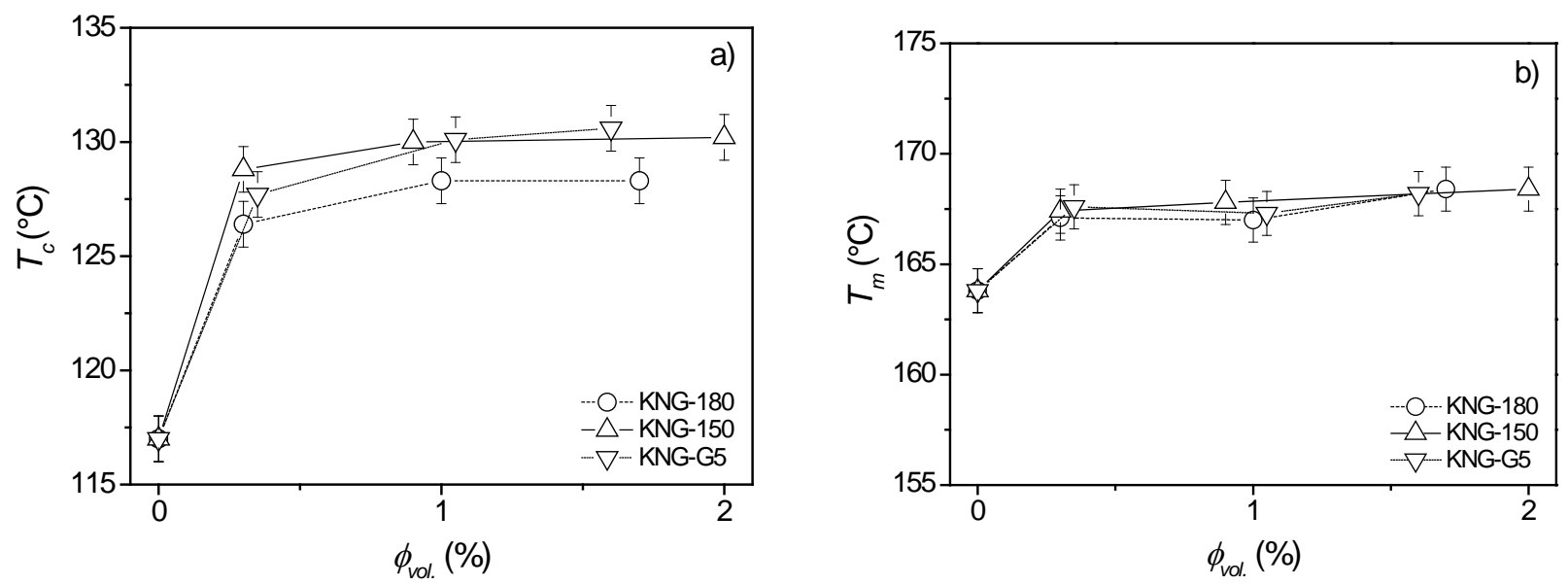

Figure 12. Crystallization (a) and melting (b) temperatures for PP/GNP composites as a function of GNP volume fraction $\phi_{v o l}$. The lines are just to guide the eyes 
As mentioned below, the addition of GNPs increases the crystallization [Figure 12(a)] and melting [Figure 12(b)] temperatures, highlighting a nucleating agent role of GNPs. ${ }^{16,17}$ Since the differences between melting temperatures $T_{m}$ of various composites were small, the discussion is focused on crystallization temperature $T_{c}$ evolution. Indeed, $T_{C}$ increases from 117 to $\sim 127^{\circ} \mathrm{C}$ by adding KNG180 nanoplatelets while the increase is more marked by adding KNG-150 or KNG-G5 (up to $130^{\circ} \mathrm{C}$ ), in agreement with the number of nucleating points per sample. Moreover, $T_{c}$ seems to increase only slightly for volume fractions ranging from 0.3 to 2 vol\% of GNPs.

\section{CONCLUSION}

Three families of graphene nanoplatelets (GNPs) with different sizes were melt mixed and compression molded in a polypropylene matrix. Crystallization and orientation of PP were characterized in the neat PP and in the different microcomposites. Microscale GNPs act as a nucleating agent and induce an epitaxial growth of $\alpha$ crystalline phase of PP. This nucleating effect is clearly demonstrated by:

(i) the enhancement of isothermal crystallization kinetics, particularly noticeable at high crystallization temperature;

(ii) the increase of crystallization temperature during a controlled cooling, with a maximum increase $\sim 13^{\circ} \mathrm{C}$;

(iii) the decrease of spherulite diameter, the largest variation being from 70-200 $\mu \mathrm{m}$ in neat PP to $10 \mu \mathrm{m}$ in a microcomposite.

It is observed at relatively low GNP volume fraction ( $0.3 \mathrm{vol} \%)$ and an increase of concentration does not provide any substantial improvement (at least in the studied range), which suggests a saturation phenomenon. The global crystallinity is similar in all samples.

The ranking of nucleation efficiencies has been related to the total particle surface (micrometric particles) available for heterogeneous nucleation, i.e., to the particle size. The particle size also influences the morphological patterns: radial spherulitic growth for small particles, transcrystalline growth for the coarsest. 
During processing, flow orients GNPs, which influences epitaxial PP crystallization in such a way that (010) PP planes are parallel to (001) graphene ones. The results suggest a saturation of PP crystalline orientation as soon as GNP volume fraction exceeds a low value $\sim 0.3$ vol\%. Conversely, the orientation of GNPs increases with both volume fraction and thickness.

Finally, even though the crystallization property modifications of PP have only a secondary influence on mechanical properties compared to the addition of GNP themselves, it should be taken into account in the design of innovative composites.

\section{ACKNOWLEDGMENTS}

This study was carried out in the frame of the CNRS (National Center for Scientific Research, France) research group GDR PolyNano. The GDR is acknowledged for providing the different GNP samples. The authors are grateful to their colleagues Lionel Freire (polarized optical microscope) from MINES ParisTech-CEMEF and Sophie Pagnotta (TEM) from Centre Commun de Microscopie Appliquée (CCMA), University of Nice Sophia-Antipolis, Microscopy and Imaging platform Côte d’Azur (MICA) for their help in structural characterization.

\section{REFERENCES}

1. Novoselov, K. S.; Geim, A. K.; Morozov, S. V.; Jiang, D.; Zhang, Y.; Dubonos, S. V.; Grigorieva, I. V.; Firsov, A. A. Science 2004, 306, 666.

2. $\quad$ Kim, H.; Abdala, A. A. ; Macosko C. W. Macromolecules 2010, 43, 6515.

3. Mukhopadhyay, P.; Gupta, R. K. Graphite, Graphene and their Polymer Nanocomposites; CRC Press, Taylor \& Francis Group: Boca Raton, 2012.

4. Zhao, W.; Wu, F.; Wu, H.; Chen, G. J. Nanomater. 2010, Article ID 528235.

5. $\quad$ Chen, G.; Wu, C.; Weng, W.; Wu, D.; Yan, W. Polymer 2003, 44, 1781.

6. Beuguel, Q.; Mija, A.; Vergnes, B.; Peuvrel-Disdier, E. Polym. Eng. Sci. 2017, 8 pp., doi:10.1002/pen.24803.

7. Monasse, B.; Haudin, J. M. Colloid Polym. Sci. 1985, 263, 822.

8. $\quad$ Libster, D.; Aserin, A.; Garti, N. Polym. Adv. Technol. 2007, 18, 685. 
9. Rybnikář, F. J. Appl. Polym. Sci. 1989, 38, 1479.

10. Maiti, P.; Nam, P. H.; Okamoto, M.; Hasegawa, N.; Usuki, A. Macromolecules 2002, 35, 2042.

11. Perrin-Sarazin, F.; Ton-That, M.-T.; Bureau, M. N.; Denault, J. Polymer 2005, 46, 11624.

12. Branciforti, M. C.; Oliveira, C. A.; de Sousa, J. A. Polym. Adv. Technol. 2010, 21, 322.

13. Song, P.; Cao, Z.; Cai, Y.; Zhao, L.; Fang, Z.; Fu, S. Polymer 2011, 52, 4001.

14. Xu, J.-Z.; Chen, C.; Wang, Y.; Tang, H.; Li, Z.-M.; Hsiao, B.S. Macromolecules 2011, 44, 2808.

15. Xu, J. Z.; Liang, Y. Y.; Huang, H. D.; Zhong, G. J.; Lei, J.; Chen, C.; Li, Z. M., J. Polym. Res. 2012, 19, doi:10.1007/s10965-012-9975-5.

16. El Achaby, M.; Arrakhiz, F.-E.; Vaudreuil, S.; el Kacem Qaiss, A.; Bousmina, M.; FassiFehri, O. Polym. Compos. 2012, 33, 733.

17. Ferreira, C. I. I.; Dal Castel, C.; Oviedo, M. A. S. A. S.; Mauler, R. S. S. Thermochim. Acta 2013, 553, 40.

18. Yuan, B.; Bao, C.; Song, L.; Hong, N.; Liew, K. M.; Hu, Y. , Chem. Eng. J. 2014, 237, 411.

19. Zhao, S.; Chen, F.; Huang, Y.; Dong, J.-Y. Y.; Han, C. C. Polymer 2014, 55, 4125.

20. Yang, S.; Li, Y.; Liang, Y.-Y.; Wang, W.-J.; Luo, Y.; Xu, J.-Z.; Li, Z.-M. RSC Adv. 2016, 6, 23930.

21. Fiorentino, B.; Fulchiron, R.; Bounor-Legaré, V.; Majesté, J.-C. C.; Leblond, J. C.; DuchetRumeau, J. Appl. Clay Sci. 2015, 109-110, 107.

22. Avrami, M. J. Chem. Phys. 1940, 8, 212.

23. Bandeira, B.; Lewis, E. L. V.; Barton, D. C.; Ward, I. M. J. Mater. Sci. 2016, 51, 228.

24. Na, B.; Wang, K.; Zhang, Q.; Du, R.; Fu, Q. Polymer 2005, 46, 3190.

25. Zhao, M.; Ming, B.; Kim, J. W.; Gibbons, L. J.; Gu, X.; Nguyen, T.; Park, C.; Lillehei, P. T.; Villarrubia, J. S.; Vladár, A. E.; Liddle, J. Nanotechnology 2015, 26, 085703, 12 pp.

26. Norton, D. R.; Keller, A. Polymer 1985, 26, 704.

27. Samuels, R. J. J. Polym. Sci. Polym. Phys. Ed. 1975, 13, 1417.

28. Causin, V.; Marega, C.; Marigo, A.; Ferrara, G.; Ferraro, A. Eur. Polym. J. 2006, 42, 3153.

29. Pavlov, V. I. Fiziko-Khimicheskaya Mekhanika Materialov 1968, 4, 598.

30. Huan, Q.; Zhu, S.; Ma, Y.; Zhang, J.; Zhang, S.; Feng, X.; Han, K.; Yu, M. Polymer 2013, $54,1177$. 
31. Tabatabaei, S. H.; Carreau, P. J.; Ajji, A. Polymer 2009, 50, 4228. 


\section{TABLES}

Table 1. Main characteristics of PP matrix

\begin{tabular}{c|c|c|c|c|c|c|c} 
Matrix & Density & $M_{n}\left(\mathrm{~g} \cdot \mathrm{mol}^{-1}\right)$ & $M_{w}\left(\mathrm{~g} \mathrm{~mol}^{-1}\right)$ & $\begin{array}{c}T_{g} \\
\left({ }^{\circ} \mathrm{C}\right)\end{array}$ & $\begin{array}{c}T_{m} \\
\left({ }^{\circ} \mathrm{C}\right)\end{array}$ & $\begin{array}{c}T_{c} \\
\left({ }^{\circ} \mathrm{C}\right)\end{array}$ & $\begin{array}{c}\eta_{0} \\
(\mathrm{~Pa} . \mathrm{s})\end{array}$ \\
\hline PP & 0.9 & 59,000 & 205,000 & -10 & 165 & 117 & 1,460
\end{tabular}

Table 2. Bulk density, density, carbon content, particle diameter $d$, thickness $e$ and specific area of GNP, data given by the supplier

\begin{tabular}{|c|c|c|c|c|c|c|}
\hline $\begin{array}{c}\text { Graphene } \\
\text { nanoplatelets }\end{array}$ & $\begin{array}{c}\text { Bulk } \\
\text { density }\end{array}$ & Density & $\begin{array}{c}\text { Carbon } \\
\text { content } \\
\text { (wt } \%)\end{array}$ & $\begin{array}{c}d \\
(\mu \mathrm{m})\end{array}$ & $\begin{array}{c}e \\
(\mathrm{~nm})\end{array}$ & $\begin{array}{c}\text { Specific } \\
\text { area } \\
\left(\mathrm{m}^{2} / \mathrm{g}\right)\end{array}$ \\
\hline KNG-180 & 0.15 & \multirow{3}{*}{2.25} & $>99.5$ & $8-100$ & $\begin{array}{c}< \\
100\end{array}$ & 35 \\
\hline KNG-150 & 0.2 & & $>98$ & $1-20$ & $<15$ & $30-60$ \\
\hline KNG-G5 & 0.1 & & $>99$ & $0.1-5$ & $<5$ & - \\
\hline
\end{tabular}




\section{FIGURE CAPTIONS}

Figure 1. GNP length $L$ (a) and thickness $e$ (b) distributions in the microcomposites measured by TEM

Figure 2. PP/0.3 vol\% KNG-G5 microcomposite observed by SEM after surface polishing (a) and optical microscopy in the molten state between glass slides (b)

Figure 3. Optical images of PP crystallization at $T=135^{\circ} \mathrm{C}$, for PP matrix (a-c) and PP/KNG-180 (d-f), KNG-150 (g-i) and KNG-G5 (j-l) microcomposites, with $\phi_{\text {vol. }} \sim 0.3$ vol\% of GNPs. All observations are reported with the same magnification on $5 \mu \mathrm{m}$ thickness films

Figure 4. Crystallization kinetics at $135^{\circ} \mathrm{C}$ for PP matrix and PP/KNG-180, KNG-150 and KNG-G5 microcomposites, with 0.3 vol\% of GNPs.

Figure 5. Crystallization half-time $\left(t_{1 / 2}\right)$ (insert represents a zoom on low values of $\left.t_{1 / 2}\right)$ (a) and Avrami exponent (b) at 130, 135 and $140^{\circ} \mathrm{C}$ for PP matrix; PP/KNG-180, KNG-150 and KNG-G5 microcomposites with $\sim 0.3$ vol\% of GNPs. The lines are just to guide the eyes

Figure 6. Enlarged optical image of PP/0.3 vol\% KNG-180 microcomposite at the end of the crystallization.

Figure 7. Pole figures of PP: (110) (a, c, f, i) and (040) (b, d, g, j), and of GNPs: (002) (e, h, k), for PP matrix (a, b) and PP/KNG-180 (c, d, e), KNG-150 (f, g, h) and KNG-G5 (i, j, k) composites, with $1.8 \mathrm{vol} \%$ of GNPs 
Figure 8. Orientation triangles of PP for the neat matrix and PP/KNG-180, KNG-150, KNG-G5 microcomposites with 1.8 vol\% of GNPs, where $\mathrm{Z}$ axis represents the specimen normal, and $\mathrm{X}, \mathrm{Y}$ axes are in the specimen plane.

Figure 9. (a) Diffractograms of PP matrix and PP/KNG-180 microcomposites at $\chi=0^{\circ}$, (b) zooms for the (110), (040) and (002) reflections

Figure 10. Integrated diffraction intensity of (110) (a), (004) (b) and (002) (c) reflections for $\mathrm{PP} / \mathrm{GNP}$ microcomposites at $\chi=0^{\circ}$ as a function of GNP volume fraction $\phi_{v o l}$. The lines are just to guide the eyes

Figure 11. DSC thermograms for PP/KNG-180 composites, during the crystallization after a first melting step to erase thermal history (a) and the second melting (b). The cooling and heating rates are of $10^{\circ} \mathrm{C} / \mathrm{min}$

Figure 12. Crystallization (a) and melting (b) temperatures for PP/GNP composites as a function of GNP volume fraction $\phi_{\text {vol. }}$. The lines are just to guide the eyes 